\title{
La noción de naturaleza en Aristóteles en el marco de sus críticas a Platón
}

\author{
SILVANA GABRIELA DI CAMILLO \\ Universidad de Buenos Aires \\ Universidad Nacional de La Plata
}

Resumen: En este trabajo, me propongo explicitar la noción aristotélica de naturaleza en el marco de sus críticas a Platón. En primer lugar, examinaré muy brevemente la propuesta de Platón en el Fedón y las críticas de Aristóteles a las Ideas como causas en Metafísica I 9; en segundo lugar, analizaré la definición de phýsis en Física II 1 como principio inmanente de movimiento; finalmente, intentaré mostrar cómo esa noción puede comprenderse mejor en el marco de la reapropiación y crítica de Platón, no solo por su característica inmanencia sino también por su eternidad a través de la generación natural. La phýsis, en Aristóteles, permite dar cuenta tanto de las propiedades esenciales cuanto de los procesos que experimentan los entes naturales.

Palabras clave: phýsis, Ideas, separación, inmanencia, eternidad. 


\title{
The Notion of Nature in Aristotle in the Context of His Criticisms to Plato
}

\begin{abstract}
In this paper, I propose to explain the Aristotelian notion of nature in the context of his criticisms to Plato. Firstly, I will briefly consider Plato's proposal in the Phaedo and Aristotle's criticisms of Ideas as causes in Metaphysics I 9; secondly, I will analyze the definition of physis in Physics II 1 as an inner principle of motion; finally, I will try to show how this notion can be better understood in the context of Plato's appropriation and criticism, not only for its characteristic immanence but also for its eternity through the natural generation. The Aristotelian notion of physis allows to account for both the essential properties and the processes experienced by natural entities.
\end{abstract}

Key-words: $p h y s i$, Ideas, separation, inmanence, eternity.

T a noción de phýsis en Aristóteles es tan relevante que casi la mitad del corpus conservado está abocado a la ciencia de la naturaleza. En un conocido pasaje del libro VI de la Metafísica, 1025b18-1026a23, Aristóteles distingue la física de las matemáticas y de la teología porque la primera se ocupa de entes inseparables de su materia y movimiento, mientras que las otras ciencias teóricas mencionadas tienen por objeto entidades inmóviles. Es importante tener en cuenta este pasaje de la Metafísica desde el inicio porque, como sugiere Vigo (2007: 65), lo que delimita el ámbito de competencia de la física y la distingue de las otras ciencias teóricas es el hecho de que sus objetos están esencialmente caracterizados por el fenómeno del movimiento. En tanto ciencia, la física deberá por tanto estudiar los principios y causas de las entidades naturales con el objeto de explicar no solo lo que ellas son sino también el modo en que se generan, se comportan y se mueven. También para Platón, en el Fedón, la indagación sobre la phýsis implica investigar las causas del ser, de la generación y corrupción de las cosas sensibles y, como es bien sabido, propone allí a las Ideas como causas. Aristóteles, por su parte, considera que las Ideas platónicas, en virtud de su separación, no pueden cumplir la función de causas del ser y del devenir de las cosas sensibles, negando la verdad de las afirmaciones del Fedón. En este trabajo, me interesa desarrollar la noción aristotélica de phýsis en relación con las críticas a Platón, partiendo de la hipótesis de que dicha noción intenta conjugar y dar cuenta del ser y del movimiento propio de 
los entes fisicos. ${ }^{1}$ En primer lugar, examinaré muy brevemente la propuesta de Platón en el Fedón y las críticas de Aristóteles a las Ideas como causas en Metafísica I 9, cuyo blanco es la separación; en segundo lugar, analizaré la definición de phýsis en Física II 1 como principio inmanente de movimiento con especial atención al criterio demarcatorio entre entes naturales y artificiales; finalmente, intentaré mostrar cómo esa noción puede comprenderse mejor en el marco de la reapropiación y crítica de Platón, no solo porque la inmanencia de la forma es una clara alternativa a la separación de las Ideas, sino porque Aristóteles conserva el carácter inengendrado e incorruptible de la forma, sin necesidad de separarla de la materia y del movimiento, a través de su reproducción en otros individuos de la misma especie. La phýsis, en Aristóteles, permite dar cuenta tanto de las propiedades esenciales cuanto de los procesos que experimentan los entes naturales.

\section{Las causas de la generación y corrupción en el Fedón y las críticas de Aristóteles}

Ta discusión acerca de las causas en el Fedón ${ }^{2}$ (96a 8- b 1 y 100c

L3-7) forma parte del argumento final a favor de la inmortalidad del alma. En un primer momento, Sócrates critica las teorías de sus predecesores acerca de la causalidad. Dichas teorías eran muy diferentes entre sí, pero compartían el rasgo de explicar los procesos de generación y corrupción apelando únicamente a causas de tipo material y a procesos de carácter mecánico (véase Vigo 2009: 133-135). Por ejemplo, el crecimiento se explicaba por la adición de carnes a otras carnes; la muerte, por disolución, disgregación, de partes materiales. Pero este tipo de explicaciones, a juicio de Sócrates, son insuficientes:

Pero llamar causas a las cosas de esa clase es demasiado absurdo. Si uno dijera que, sin tener cosas semejantes, es decir, tendones y huesos y todo lo demás que tengo, no sería capaz de hacer lo que decido, diría cosas ciertas. Sin embargo, decir que hago lo que hago a causa de ellas, y eso al actuar con inteligencia, y no por la elección de lo mejor, sería un enorme y excesivo

\footnotetext{
${ }^{1}$ Giardina 2006, 2011 argumenta en esta dirección.

${ }^{2}$ Existe un gran número de trabajos sobre el estatuto de las causas en el Fedón. Fronterotta 1999: 397-415 plantea un buen estado de la cuestión y evalúa las clásicas posiciones de Vlastos, Bluck y Allen. Pueden consultarse con provecho también los artículos de Fine 1987: 69-112; Fischer 2002: 650-680 y Sharma 2009: 137-177.
} 
abuso de expresión. Pues eso es no ser capaz de distinguir que una cosa es lo que es la causa de las cosas y otra aquello sin lo cual la causa no podría nunca ser causa (Fedón 99a3-b3, trad. C. García Gual).

A juicio de Sócrates, este tipo de explicaciones mecánicas no distinguen las verdaderas causas de las condiciones necesarias para que la verdadera causa opere. Así, explicarían su permanencia en la prisión aludiendo a sus huesos y tendones, que son solo las condiciones sin las cuales no podría estar sentado allí, pues la verdadera causa es su decisión de obedecer la ley y soportar la pena antes que huir y desertar. La primera crítica a las teorías precedentes de la causalidad, pues, es su indistinción entre condiciones necesarias y verdaderas causas. Las verdaderas causas son teleológicas porque es necesario explicar por qué la naturaleza está organizada según lo mejor, pero no es en el Fedón donde desarrolla esta explicación sino en Timeo (véase $46 \mathrm{c}-47 \mathrm{a}, 68 \mathrm{e}-69 \mathrm{~d})$.

Sócrates dirige una segunda crítica a estas teorías científicas porque encuentra ciertas posiciones contradictorias. Así, por ejemplo, la adición de un uno a otro uno es causa del dos, pero también la división de uno es causa del dos: ¿cómo es posible que el mismo efecto (en este caso: el dos) sea producido por causas contrarias? A su vez, algo puede ser mayor por una cabeza, pero también puede ser menor por una cabeza: ¿cómo es que la misma causa produce efectos contrarios? Más aún - prosigue Platón-, la cabeza, que es pequeña, hace a alguien mayor: ¿cómo es que la causa de una propiedad tiene la propiedad contraria a la que debe producir? (véase Fedón 100e-101d).

A partir de la crítica a las teorías anteriores, es posible inferir tres "leyes generales" de causalidad en Platón: ${ }^{3} 1$ ) el mismo efecto no puede ser producido por causas opuestas; 2) la misma causa no puede producir efectos opuestos; 3) la causa X, responsable del efecto $\mathrm{x}$, no podrá ser ella misma no-x, sino que tendrá que ser $\mathrm{x}$. Es importante advertir que estas leyes de causalidad marcan las condiciones que debe cumplir una verdadera causa para Platón:

Conque, si alguien afirma que cualquier cosa es bella, o porque tiene un color atractivo o una forma o cualquier cosa de ese estilo, mando a paseo todas las explicaciones - pues me confundo con todas las demás- y me atengo sencilla, simple y, quizás, ingenuamente a mi parecer: que no la hace bella ninguna otra cosa, sino la presencia o la comunicación o la presentación en

\footnotetext{
${ }^{3}$ Así se expresan Sedley 1998: 121 y Hankinson 1998: 84-102. Véanse también Annas 1982: 316 y Gill 2012: 22-23.
} 
ella en cualquier modo de aquello que es lo bello en sí. Eso ya no lo preciso con seguridad; pero sí lo de que todas las cosas bellas son bellas por la belleza. Me parece que eso es una respuesta firme tanto para mí como para responder a otro, y manteniéndome en ella pienso que nunca caeré en error, sino que es seguro, tanto para responderme a mí mismo como a cualquier otro, que por lo bello son bellas las cosas bellas. ¿No te lo parece también a ti? (100c8-e2).

La verdadera causa debe ser universal, en el sentido de que es la única entidad que explica todos los casos particulares. En el pasaje citado, es la Idea de lo bello la única entidad por la cual todas las cosas bellas son bellas. Y, a su vez, la verdadera causa debe ser absoluta, en tanto es aquella entidad que posee la propiedad plenamente, sin relatividad alguna. ${ }^{4}$ En el pasaje, el color brillante o la figura, que pueden ser tanto bellos como feos, no podrían ser aquello en virtud de lo cual algo es bello. Esa relatividad, esa copresencia de opuestos tan propia del ámbito sensible, impide que puedan desempeñarse como la verdadera causa de la belleza de las cosas sensibles (Fine 1995: 58), causa que debe ser, en cambio, absoluta.

Sócrates atribuye a las Ideas el papel de causas de las propiedades sensibles. Como señala Vigo (2009: 138):

Sócrates establece el siguiente principio: dado un X que es "X en sí mismo" (p. ej. lo Bello mismo), todas las demás cosas que poseen la correspondiente propiedad "x" (i.e. belleza) y reciben la misma denominación que X mismo (i. e. "bello"), lo hacen en razón de su relación con X mismo, de modo tal que $\mathrm{X}$ mismo constituye la causa en virtud de la cual poseen la correspondiente propiedad y reciben la correspondiente denominación.

En efecto, las cosas sensibles adquieren de las Ideas sus propios nombres (eponimia): a las cosas les pertenece temporalmente el nombre que pertenece eternamente a las Ideas con las que guardan alguna relación y por la duración de esta relación. ${ }^{5}$ La Idea, en cuanto es aquello que es por sí, se diferencia de las cosas sensibles justamente en esto, porque estas cosas son lo que son (por ejemplo, bellas) de modo derivativo, por alguna relación con la Idea.

\footnotetext{
${ }^{4}$ Annas 1982: 316 también menciona entre las motivaciones de considerar a las Ideas como aitíai el principio de que la causa es mayor que el efecto.

${ }^{5}$ Véase Fedón 78d10-e2; 102a10-b2; c10-d2; 103b6-c1; e2-5. Platón retoma la cuestión de la eponimia en el contexto más amplio de la indagación sobre la participación de las cosas sensibles en las Ideas en Parménides 130e4-131a1.
} 
En general, la relación entre los niveles de la realidad es denominada "participación" (méthexis). En este pasaje menciona tres términos para referirse a la relación entre Ideas y particulares sensibles: participación (metékhei, 100c5), comunicación (koinonía, 100d5) y presencia (parousía, 100d6). ${ }^{6}$ Sócrates insiste en la necesidad de la relación participativa, pero es consciente de la dificultad de poner en relación dos ámbitos completamente heterogéneos, dejando así voluntariamente de lado el problema de su articulación y de su modalidad en el Fedón (100d6-7).

En suma, en este famoso pasaje autobiográfico, Sócrates critica las teorías de sus predecesores, señala la importancia de las explicaciones teleológicas (aunque no las ofrezca en el Fedón) y propone a las Ideas como causas, en tanto constituyen las únicas entidades que cumplen los requisitos de una verdadera causa: ser universales y absolutas.

Aristóteles, por su parte, en el contexto del libro I de la Metafísica, en el que examina las tesis de sus predecesores en torno al problema de la causalidad, dedica el capítulo 9 a evaluar en qué medida las Ideas platónicas pueden ejercer una función causal respecto de las cosas sensibles. ${ }^{7}$ En este contexto, formula a su antecesor una serie de objeciones. Estas objeciones se pueden articular en cuatro grandes dificultades. El capítulo presenta una primera crítica general en la que se señala que Platón, al intentar conocer las causas de la realidad sensible, introdujo otras entidades distintas de ellas, las Ideas, de manera que no ha simplificado, como suele hacerse a la hora de explicar algo, sino que ha operado una duplicación (990a34-b8).

Sigue luego la crítica a los argumentos que los platónicos utilizaban para probar la existencia de Ideas, argumentos que Aristóteles menciona muy elípticamente, pero que habían sido desarrollados en un tratado, perdido para nosotros, llamado Sobre las Ideas. Según Aristóteles, estos argumentos en favor de las Ideas muestran una gran fragilidad: por una parte, no alcanzan su objetivo declarado porque no logran probar que haya Ideas sino solo universales y, por otra, conducen a la admisión de Ideas inaceptables para los propios platónicos (990b8-17).

${ }^{6}$ De una relación de participación se habla también en Fedón 102b y en Banquete 211b. En la República se menciona a la koinonía en VI 476a, pero enseguida se habla explícitamente de participación (476d). De una relación de imitación se habla en República 500c, además (y en general) en Fedro 250a-b, en Parménides 132d y en Timeo 39d-e, 48e-50a, 50c.

${ }^{7}$ Existe un gran número de comentarios, libros y artículos que ofrecen una interpretación de las críticas de Aristóteles a Platón en Metafísica I 9. No pueden dejar de citarse los comentarios de Ross, Reale y Berti a sus respectivas traducciones de la Metafísica ni las monumentales obras de Robin 1908 y Cherniss 1944. Un valioso artículo es el de Fronterotta 2010: 93-119. 
Dejo de lado estas dos primeras objeciones ${ }^{8}$ para concentrarme en las dos últimas: las críticas a las Ideas como causas de la generación y corrupción de las cosas sensibles, por una parte, y las críticas a la participación e imitación como modalidades de relación causal, por otra.

En Metafísica 991a8-14, Aristóteles define la dificultad, que considera la mayor de todas, en estos términos:

Pero la mayor dificultad con la que alguien podría encontrarse es esta: ¿en qué contribuyen las Ideas a las cosas sensibles, sea a aquellas de las sensibles que son eternas, sea a las que se generan y corrompen? Pues ellas no son causas ni de sus movimientos ni de ningún cambio de ellas. Por lo demás, ellas tampoco ayudan para el conocimiento de las otras cosas (puesto que no son la esencia de ellas, dado que si lo fueran estarían en ellas, ni para su ser, ya que no son inmanentes a las cosas que de ellas participan (Metafísica 991a8-14 =1079b12-18, trad. Santa Cruz-Crespo).

En este pasaje, Aristóteles define la dificultad más grande, aquella según la cual las Ideas no sirven para explicar las cosas sensibles. Allí señala que las Ideas:

I) no son causas de generación y corrupción pues esto implica movimiento: se supone a) que para producir un movimiento es preciso un motor que mueva y esté en contacto con las cosas movidas ${ }^{9}$ y b) que las Ideas son inmutables y separadas;

II) no son causas del ser de las cosas pues no son inmanentes a ellas: se supone a) que las Ideas son separadas y b) que las causas formales son inseparables de sus sujetos; ${ }^{10}$

III) no son causas del conocimiento de la cosa pues no constituyen su esencia: se supone a) que las Ideas están separadas de las cosas y b) que se conoce la cosa cuando se conoce su esencia. ${ }^{11}$

\footnotetext{
${ }^{8}$ Para un análisis detallado de las dos primeras objeciones, véase Di Camillo 2012: 62-75.

${ }^{9}$ En Física 202a6-9 Aristóteles sostiene que el motor tiene que estar en contacto con lo movido, por lo que puede inferirse que una Idea separada no puede causar movimiento. Véase también Metafísica 991b3-9 donde señala que, aunque las Ideas existan y las cosas sensibles participen en ellas, no habrá generación a menos que exista una causa motriz.

${ }^{10} \mathrm{La}$ forma, que es la causa del ser del ente natural, no es separable más que conceptualmente; Física 193b3-5.

${ }^{11}$ Véase Metafísica 1031b3-9. La definición, principio de la ciencia, es para Aristóteles el enunciado de la esencia, de lo que cada cosa es por sí misma (Metafísica 1029b13-14), mientras que lo que es accidental y no necesario no es objeto de ciencia (Segundos Analíticos 71b15$16 ; 73 \mathrm{a} 21 ; 74 \mathrm{~b} 6)$.
} 
Aristóteles puede concluir entonces que la teoría de las Ideas es inútil para explicar la realidad sensible, pues ellas no son causas del movimiento, ni del ser, ni del conocimiento de las cosas sensibles. En esta argumentación aristotélica una o más de las premisas están ausentes, pero pueden ser reconocidas sin dificultad. La premisa implícita común a todos los argumentos está dada por la separación de la Idea (Ib; IIa; IIIa): la Idea no puede constituir el ser de una cosa sensible, su ousía, si está separada del objeto, pero tampoco puede explicar el devenir propio de las cosas sensibles siendo inmóvil y separada. Aristóteles insiste en que las Ideas no pueden explicar el cambio en otros lugares del corpus también. ${ }^{12}$ Pero es especialmente en Acerca de la generación y corrupción 335b7-24, y haciendo explícita referencia al pasaje del Fedón 96a ss., donde Aristóteles critica a Platón el hecho de que las Ideas no cuentan como causas motrices, por lo que Platón se equivoca al considerar que la Idea realmente produce un cambio y que pueda explicar así la generación y la corrupción sin la acción de un agente. En ese tratado, Aristóteles distingue entre entes eternos, que existen por necesidad, y otros que pueden existir o no existir, que es el caso de lo generable y corruptible. Para explicar la existencia de este tipo contingente de entes, es necesario apelar a la materia y a la forma, pero también a un tercer factor causal: el motriz. Esa función motriz no puede cumplirla la Idea ya que, siendo eterna, la generación debería ser continua y necesaria y no intermitente como lo es. La falta de una causa motriz es una de las principales críticas a los platónicos en la Metafísica, al punto de afirmar que han convertido a la filosofía en matemáticas, por separar el ente natural de su movimiento esencial. ${ }^{13}$

Además de negar eficacia causal a las Ideas, en su cuarta crítica Aristóteles intentará mostrar que todos los modos de relación que Platón estableció entre las Ideas y las cosas son inconsistentes. Las cosas sensibles no pueden ser "a partir de las Ideas" en ninguno de los modos usuales que los propios platónicos propusieron, vale decir, ni por participación ni por imitación. ${ }^{14}$ La hipótesis de la participación no resuelve la dificultad pues, como señala Aristóteles un poco antes, en 990b27-991a8, si las Ideas son

\footnotetext{
${ }^{12}$ Véase Metafísica $1071 \mathrm{~b} 14-17$ y 1075b27-28.

${ }^{13}$ Véase Metafísica 991a8-b9; 992a24-b1. En Física II 2 se aclara que separar conceptualmente las formas es lícito en un abordaje matemático, pero en un abordaje físico conduce a serios errores dado que las formas naturales son capacidades de los cuerpos para funcionar de distintos modos. Véase Lennox 2008: 183.

${ }^{14}$ Metafísica 991a19-20. Sigo aquí la segunda de las exégesis propuestas por Alejandro (Comentario a la Metafísica, 100.22-30), entendiendo que por modos usuales de procedencia hay que interpretar los propuestos por los platónicos y no por Aristóteles.
} 
participables por parte de las cosas sensibles, entonces tendrán que compartir con las cosas sensibles una idéntica forma y habrá entre ellas un elemento común, lo cual conduce a un regreso al infinito. ${ }^{15}$ Por otro lado, si no hay, de ninguna manera, una comunidad entre las Ideas y las cosas participantes, las cosas no podrán adquirir de las Ideas su propio nombre y su propia esencia y se dará entre los dos planos separados de la realidad una relación de simple "homonimia", una mera coincidencia nominal. ${ }^{16}$

La relación copia-modelo tampoco proporciona una explicación de la causalidad formal de las Ideas-modelos con respecto a las copias sensibles, porque podrían existir muchas cosas sensibles que se asemejasen entre sí, pero eso no querría decir que ellas sean copia de un modelo. Es claro que en su crítica a la Idea como modelo Aristóteles denuncia que la relación de semejanza no supone necesariamente la de imitación. Pero a la vez, creo que aquí también vale la crítica que Aristóteles había realizado a la relación como participación, en tanto la relación de semejanza implica la comunidad específica entre los semejantes. Si existe tal comunidad de naturaleza entre el ámbito inteligible y el sensible, es necesario, por la lógica misma de los argumentos a favor de las Ideas, postular una nueva Idea que explique esa comunidad, lo cual conduce a una regresión infinita. Inversamente, si esta comunidad no existe, entonces no puede haber entre el modelo y la copia más que una coincidencia puramente nominal, una mera homonimia casual, es decir, modelos y copias comparten el nombre pero no su naturaleza, por lo que el tener un nombre común no asegura ninguna conexión real y las Ideas perderían su carácter causal. ${ }^{17}$

Esta es la razón por la que Aristóteles agrega que postular las Ideas separadas y definirlas a la vez como "modelos" de las cosas sensibles que se asemejan a ellas, o que de ellas en algún modo participan, significa "proferir palabras vacías y usar imágenes poéticas" (kenologeîn estì kaì metaphoràs légein

${ }^{15}$ De acuerdo con un argumento muy presente en los diálogos de Platón (véanse, Crátilo 439c7-d1; República 507b2-9 y 596a5-8; Fedro 249b6-c1; Parménides 131a7-8, e3-4; 132a y Filebo $14 c 7-15 c 3)$, toda vez que un conjunto de cosas tiene una propiedad en común, debemos postular una Idea que sea la causa de esa propiedad en común. Por tanto, si hay una propiedad en común entre Ideas y cosas participantes, deberíamos postular otra Idea que sea la causa de esa propiedad y así al infinito.

${ }^{16}$ Esta doble consecuencia de la separación de las Ideas aparece también en Metafísica 1059a10-4. Véase Centrone 2002. Para la cuestión de la relación entre homonimia y separación, véase Di Camillo 2012: 193-230.

${ }^{17}$ Recuérdese que, en la generación natural, para Aristóteles, generante y generado son uno en forma, como explicitaré más adelante. 
poietikás). ${ }^{18}$ Una frase vacía no refiere a nada y, por lo tanto, tampoco puede decirse nada sobre su verdad y falsedad; una metáfora poética carece del rigor propio del lenguaje científico y poco o nada puede aportar a la solución de un problema filosófico como el de la causalidad. Al caracterizar la teoría de la participación como "una palabra vacía y una metáfora poética", hace posar sobre ella todas las limitaciones que habitualmente se asocian con las metáforas. La advertencia de Aristóteles es que está lejos de ser obvio cómo el ámbito de lo sensible y el de lo inteligible pueden encontrarse en relación el uno con el otro y cómo, por consiguiente, debemos concebir la relación de participación.

Consideradas en su conjunto, las críticas de Aristóteles a la causalidad de las Ideas son altamente concisas, pero presuponen doctrinas aristotélicas que Platón podría muy bien no haber aceptado. En tal sentido, podría decirse que la crítica de Aristóteles es externa a la doctrina platónica, basada en su propia suposición de que la forma es inmanente y permite explicar tanto el ser como el movimiento de los entes naturales. Es importante subrayar, sin embargo, que la forma aristotélica conserva ciertos rasgos de la Idea, en tanto ambas cumplen un importante papel tanto para el conocimiento como para el ser de lo particular. Pero si bien es preciso integrar lo que otros dijeron acerca del problema, Aristóteles aclara que "no debemos repetir los mismos errores" de los filósofos precedentes. ${ }^{19}$ Del análisis de sus críticas a Platón en Metafísica I 9 es posible concluir que, a los ojos de Aristóteles, la aporía fundamental de la concepción platónica de la causalidad de las Ideas consiste en su separación de las cosas sensibles. ${ }^{20} \mathrm{El}$ examen crítico de las Ideas como causas conduce a Aristóteles a proponer una alternativa que solucione las dificultades halladas en la teoría platónica y es en este marco en que conviene situar su definición de phýsis, entendida como causa del ser y del devenir de las entidades naturales.

\section{La noción de naturaleza en Física II 1}

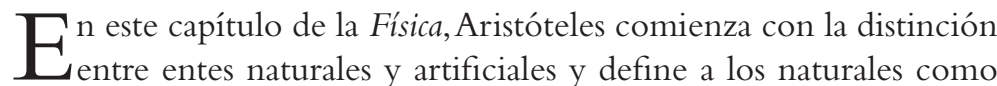
aquellos que tienen en sí mismos la causa de sus cambios. Luego plantea la cuestión de si la naturaleza de un ente natural debe ser entendida como su

\footnotetext{
${ }^{18}$ Metafísica 991a20-2. Véase también Metafísica 1079b23-6.

${ }^{19}$ Véase Metafísica1076a12-4.

${ }^{20}$ Véase Metafísica 1086b6-7.
} 
materia o más bien su forma. La exposición tiene tres partes: en la primera (192b8-193a2), Aristóteles ofrece la caracterización general de naturaleza y de los objetos que se producen por naturaleza; en la segunda (193a9-30), ofrece argumentos para considerar a la phýsis como materia y en la tercera (193a30-193b21), argumenta a favor de la phýsis como forma.

Al comienzo del texto ya aparece la naturaleza como si fuera una causa: "Entre los entes, unos son por naturaleza (phýsei), otros, en cambio, por otras causas (állas aitías)" (192b8-9). Me interesa subrayar estas líneas del inicio porque phýsis en Aristóteles es siempre la phýsis de algo, es decir que la naturaleza no es una entidad sino un principio causal que explica la manera en que una entidad es y se comporta.

A continuación, Aristóteles traza una distinción entre los artefactos y los entes naturales. Lo propio de los entes naturales es poseer en sí mismos (en heautôi) un principio de movimiento y de reposo, y especifica los tres modos en que puede haber movimiento o cambio, esto es según el lugar como traslación, según la cantidad como crecimiento y disminución y según la cualidad como alteración. Los objetos producidos por la técnica, como por ejemplo una cama o un vestido, no tienen esta tendencia natural al cambio, pero en la medida en que tales objetos están hechos de piedra o de tierra padecerán las tendencias propias de esos componentes naturales, no por sí, sino porque accidentalmente están hechos de un elemento natural que sí tiene esa tendencia al cambio. Esa tendencia, de hecho, no es otra cosa que la presencia inmanente del principio natural en el ente. Es en este punto, en 192b21-23, donde define la noción de naturaleza como "un cierto principio y causa del moverse y del permanecer en reposo de aquello a lo cual pertenece primariamente, por sí mismo y no por accidente". La definición no es transparente y conviene detenerse en cada término. El objetivo inmediato de Aristóteles es caracterizar la naturaleza en oposición a otro tipo de principio de movimiento, que es la causalidad técnica. Ambas, naturaleza y técnica, serían principios de movimiento, pero la naturaleza sería un principio interno a la cosa que sufre el movimiento, en contraste con la técnica, que es un principio externo.

Se suele indicar que la definición de phýsis comprende dos requisitos fundamentales:

1. la naturaleza es cierto principio o causa de movimiento; ${ }^{21}$

2. la naturaleza es un principio o causa de movimiento que pertenece intrínsecamente a la cosa que sufre el cambio.

\footnotetext{
${ }^{21}$ Hay un amplio debate acerca de si entender este principio de cambio como un principio activo, como un principio pasivo o como el género de estas dos clases de principio. Para una discusión de las distintas posiciones, véanse Besnier 1997, Fritsche 2010 y 2018 y Kelsey 2003.
} 
El primer requisito no es suficiente porque lo comparte con la técnica. El segundo, en cambio, marca la especificidad de la naturaleza con respecto a la técnica, pues el principio de la técnica proviene de "afuera", mientras que la naturaleza no es algo exterior sino algo inmanente al correspondiente objeto, algo que lo constituye como tal. ${ }^{22}$

Sin embargo, Aristóteles presenta el caso de un médico que se cura a sí mismo como una clara objeción a esa definición de naturaleza. Un hombre que ha sido curado es una producción del arte de la medicina. Existe una relación intrínseca entre el médico y el arte de la medicina, pero el médico es externo al enfermo que ha sido curado. No obstante, en el ejemplo de Aristóteles el principio de la producción parece interno, puesto que es el enfermo mismo el que procura su salud.

El ejemplo es importante porque revela otro requisito expresado en la definición de naturaleza, no suficientemente subrayado. La diferencia que existe entre naturaleza y técnica es identificada ahora mediante el agregado "por sí y no por accidente". Aristóteles señala que el arte médico presente en el médico que se cura a sí mismo y la naturaleza de los entes naturales tienen un elemento común, porque son ambos principios internos, y una diferencia, porque el primero es un principio interno por accidente y la segunda un principio interno por sí (192b30-32). Si la definición de naturaleza concluyera en la necesidad de que el principio de cambio sea interno, Aristóteles no podría evitar la consecuencia de que la medicina fuera naturaleza, ni que el médico, en su procedimiento de cura, procediera de acuerdo con una causalidad natural.

¿Qué significa entonces tener un principio interno? Pues la objeción del médico que se cura a sí mismo muestra que no significa simplemente que se encuentra fisicamente en su interior. Aristóteles precisa que algo es un principio interno si pertenece primariamente a aquello de lo que es principio y si es interno a él por sí y no por accidente.

El pertenecer primariamente y el "por sí" constituyen entonces los dos rasgos definitorios del concepto de principio interno de movimiento y de reposo. El significado de pertenecer primariamente ya fue ilustrado en negativo, a través de una referencia a una causa que no pertenece primariamente a aquello de lo que es principio: la materia de los artefactos. Como vimos, un artefacto tiene un principio interno solo porque aquello de lo que está constituido tiene un principio interno, o sea, solo porque su materia es un ente natural que, en cuanto tal, tiene un principio interno. Los artefactos,

${ }^{22}$ Véanse Vigo 2007: 69 y Angioni 2010: 522. 
por tanto, tienen un principio interno de manera derivada y no por sí. El principio interno les pertenece accidentalmente, por estar hechos de un componente natural que sí tiene un principio interno.

A diferencia de los artefactos, los entes naturales tienen este principio -la naturaleza- de modo no accidental sino por sí, es decir de modo esencial y no por estar compuesto accidentalmente de un ente natural. En otras palabras, el principio de movimiento de los entes naturales es un principio interno, no simplemente porque se encuentra físicamente en su interior, sino porque es causa de los movimientos contenidos en la definición de la entidad natural (Quarantotto 2005: 125-126).

Este principio es interno al ente natural por sí y no por accidente. Como ya señalé, Aristóteles se preocupa por clarificar la expresión "no por accidente" a través del ejemplo del médico que se cura a sí mismo; un hombre que ha sido curado, en tanto ha sido curado, es una producción del arte de la medicina. Pero en el ejemplo de Aristóteles el principio de la producción parece interno, puesto que es el enfermo mismo el que procura su salud. Ahora bien, el enfermo no se cura a sí mismo en cuanto enfermo, sino en cuanto médico, es decir en cuanto tiene la forma de la salud en su mente y puede provocar salud en su cuerpo. Pero esto, que el enfermo coincida con el médico, es accidental, porque lo normal es que, en el caso de los artefactos, el que tiene el principio de movimiento es externo al artefacto. En suma, los artefactos tienen su principio de movimiento fuera y, si lo tuvieran dentro, sería puramente accidental, como el caso del médico que se cura a sí mismo.

De esto parece posible inferir que la definición de naturaleza pone de relieve qué tipos de cambio experimentan las entidades naturales por ser tales, es decir, por sí mismas y no por acción de algo externo ni por referencia a algo diferente (Vigo 2007: 69).

Una vez definida la naturaleza de una cosa como el principio interno de su movimiento, Aristóteles se pregunta: ¿es la materia o la forma? En Física I 7 él ya había establecido que la materia y la forma eran los principios a partir de los cuales las entidades naturales "son y llegan a ser primariamente y no por accidente, sino cada cosa lo que se dice que es según la entidad" (190b18-19). Así, tanto la materia como la forma cumplen con el requisito señalado en la definición de phýsis, por lo que la discusión siguiente atiende, no a decidirse por una con exclusión de la otra, sino más bien a jerarquizar esos principios dando a la forma la primacía.

Aristóteles presenta el caso de aquellos que sostienen que el principio interno de movimiento es siempre y únicamente la materia, tomando como fundamento el argumento de Antifonte según el cual si se enterrara una cama de madera, el producto que surgiría sería madera, no una cama, 
por lo que se concluye que el estar constituida de madera es la phýsis de la cama, mientras que la estructura de los materiales no (193a9-17). ${ }^{23}$ Este es el punto de vista de los antiguos fisicos, quienes explicaron la realidad a partir de la causa material exclusivamente. Según Aristóteles, si este fuera el único modo de entender la phýsis, esto equivaldría a decir que la materia elemental mediante sus propiedades sería responsable de todos los movimientos a los que estos entes están sujetos, incluso de su generación (véase Rossi 2011: 53). Aristóteles admite que la naturaleza es materia, pero entendida como un sustrato (193a28-30). Según esto, lo que permanece inalterable mientras la cosa sufre modificaciones es la naturaleza entendida como sustrato. Pero considerar la naturaleza como pura materia es insuficiente, es un modo derivado de considerarla, ya que la forma posee anterioridad ontológica respecto de la materia. Por eso, Aristóteles va a ofrecer una serie de argumentos para mostrar que la forma de una entidad fisica también merece, y con mayor derecho, el título de naturaleza.

Un primer argumento a favor de la primacía de la forma como phýsis se vale de una analogía con las artes (193a30-193b6). Así como en el caso de un artefacto (por ejemplo, una cama) lo llamamos tal no por su materia sino por su forma, tampoco diremos de los elementos constituidos por naturaleza (por ejemplo, la carne, el hueso) que son carne o hueso hasta tanto no tengan la configuración propia de carne y hueso.

Un segundo argumento a favor de la forma retoma el argumento de Antifonte para mostrar que este se aplica a la forma en mayor grado, pues, si la naturaleza de una cosa es un principio inmanente que es como aquello que genera, entonces la naturaleza de un hombre debe ser su forma, en tanto "un hombre genera un hombre" (193b8-12). No es la materia lo que surge de un ser vivo, sino otro ser vivo, idéntico específicamente con su padre, de manera que las formas de las entidades naturales son heredables.

La introducción de este requisito de "heredabilidad" no debería sorprender porque es una nueva respuesta al problema de la separación platónica de las Ideas. En efecto, Platón concibe la eternidad de las Ideas en términos de separación de las Ideas respecto de los individuos generables y corruptibles de los que son causas. Ahora bien, si la forma es para Aristóteles un principio interno de movimiento y si, además, es inseparable de la materia y del movimiento propios de las entidades naturales, surge inmediatamente una pregunta: ¿cómo logra garantizar la ingenerabilidad e incorruptibilidad de la forma a pesar de la inmanencia?

${ }^{23}$ Heinemann (s.f.: 20-22) subraya que la phýsis es heredable y llama a este requisito "test de heredabilidad". 
Particularmente interesantes, para este propósito, son MetafísicaVII 8 y XII 3 en donde Aristóteles subraya muchas veces que no se genera la forma sino el compuesto de materia y forma. ${ }^{24}$ En ambos capítulos, Aristóteles aborda la ingenerabilidad e incorruptibilidad de las formas, critica a Platón por haberlas justificado recurriendo a la separación, y hace referencia a la generación natural, ilustrada mediante el ejemplo del hombre que genera un hombre, para mostrar cómo es posible dar cuenta del carácter inengendrado e incorruptible de la forma, sin necesidad de caracterizarla como una entidad separada de la materia y del movimiento.

Para explicar de manera inteligible la generación de nuevos individuos de la misma especie, basta suponer que la forma funcione como causa eficiente que gobierne la determinación de la materia en dirección a la constitución de un nuevo individuo de la misma especie. Así, algo llega a ser hombre, no por participar del hombre en sí, sino por llegar a tener la forma característica de los hombres. Sin embargo, la forma misma no se genera, sino que preexiste al proceso de generación. La pregunta que surge inmediatamente es dónde preexiste la forma antes de la generación. La respuesta es que preexiste en el generante y se comunica a través de la reproducción biológica. ${ }^{25}$ Padre e hijo serán así individuos numéricamente diferentes, pero unos en forma. Particularmente ilustrativo resulta un pasaje de Acerca del alma (415a 22-b8) en el que Aristóteles sostiene que producir un ejemplar similar a sí mismo es la función orgánica más natural: permite al padre participar de lo eterno y divino tanto como es posible, pues mientras que el reproductor no persiste, lo que es semejante a él sí.Y aquí también subraya Aristóteles que lo que persiste no es uno en número pero es uno en forma (415b7). ${ }^{26}$ Todo acto de reproducción implica la preservación de la forma que el padre transmite a su descendencia. Si suponemos que el ente generado también se reproduce, y así sucesivamente, la forma característica de la especie debería persistir indefinidamente.

Así, forma y materia son para Aristóteles principios previamente dados al proceso de generación y el nacimiento de un nuevo individuo no implica que los principios mismos estén sometidos al proceso de devenir (Angioni 2008: 227). La forma es responsable por lo que se genera sin que sea necesario separarla ni concebirla como modelo. La elíptica pero repetida frase de Aristóteles "un hombre engendra a un hombre" adquiere así un claro contenido, pues muestra que, en la reproducción de los entes naturales,

\footnotetext{
${ }^{24}$ Véanse también Metafísica 1039b26-7; 1044b21-22 y, sobre todo, 1069b35; 1070a27-29.

${ }^{25}$ Véanse Reproducción de los animales 735b32-5; 736b33-737a10; 738b3-4; 20-27; 740b2125 y Lennox 1985.

${ }^{26}$ Para la interpretación de este argumento, véase Boeri 2012: 201-202.
} 
lo que se genera tiene la misma forma que el generante. Aristóteles insiste en que cada caso de generación de un ente natural requiere la preexistencia de un ente de esa clase como su fuente de generación. ${ }^{27} \mathrm{El}$ proceso de reproducción debe verse como un ciclo en una preservación continua y eterna de la forma de una especie.

Por último, en esa misma elíptica frase está la respuesta de Aristóteles a Platón en lo que toca a un arte divino responsable de la generación de los entes naturales y de la preservación del orden natural. A su juicio, Platón ignora la clara distinción entre naturaleza y técnica y aplica la causalidad técnica al ámbito natural. Dada la neta distinción que Aristóteles estableció en la Física entre entes naturales y artificiales, basada en la presencia de un principio interno de movimiento en los naturales y la necesidad de un principio externo en los artificiales, se comprende que la figura del demiurgo introducida en el Timeo es a sus ojos una ilegítima transposición al ámbito natural de la necesidad de un principio externo y de la relación modelo copia propias del ámbito artístico y, por lo tanto, está injustificada. ${ }^{28}$

Al comentar la crítica de Aristóteles al paradigmatismo platónico en Metafísica 991a20-23, Alejandro de Afrodisia sostiene, con razón, que en la generación natural no cumple ningún papel la contemplación de un modelo. En efecto, un hombre particular es generado por otro hombre particular y un caballo por otro, pero ninguno de estos agentes -afirma Alejandroproduce contemplando modelo alguno, sino que tanto la generación cuanto la función de cada agente es algo natural. ${ }^{29}$

\section{Conclusiones}

A ntes de cerrar el análisis de la noción de phýsis en Aristóteles, A conviene recapitular algunos puntos. En primer lugar, he analizado la propuesta de Platón en el Fedón en torno a las causas de la gene-

\footnotetext{
${ }^{27}$ Véanse Metafísica 1032b30-32; 1034b13-19; Reproducción de los animales 715b8-16.

${ }^{28}$ Giardina (2011: 72) señala con razón que el orden y la regularidad son asegurados sin que sea necesario recurrir a una mente ordenadora y externa. El fin de un proceso coincide con la perfecta realización del ente, es decir, con su forma, pero está presente desde el inicio del cambio mismo direccionando el proceso hacia la realización cumplida de la forma. Es en el último argumento de Física II 1 (193b13-21) donde Aristóteles conecta por primera vez la forma con el fin de la generación, adelantando argumentos que desarrollará con detalle en Física II 8 y que quedan fuera del propósito de este trabajo.

${ }^{29}$ Véase Alejandro de Afrodisia, Comentario a la Metafísica, 101. 26-30.
} 
ración y corrupción. Allí, él proponía a las Ideas como causas en virtud de que únicamente ellas satisfacen el requisito de universalidad y poseen un carácter absoluto. A continuación, he explicitado las críticas de Aristóteles a la causalidad de las Ideas en Metafísica I 9, en las que denuncia que las Ideas no son causas del movimiento, ni del ser ni del conocimiento de las cosas sensibles en virtud de su carácter separado. Por último, he argumentado que es en el marco de la apropiación y crítica de Platón donde conviene situar la noción aristotélica de phýsis presentada en Física II 1, pues se trata de una propuesta alternativa que soslaya las dificultades que comporta la teoría de Platón. En ese capítulo de la Física puede advertirse una respuesta a la separación platónica al definir a la phýsis de los entes naturales como un principio interno de movimiento y de reposo, que constituye a la vez su ousía, de manera que esta noción conjuga en sí la causa que hace que ellos sean lo que son y la que hace que estén sometidos a ciertos procesos de cambio, como el crecimiento por el que alcanzan su forma adulta. Si bien Aristóteles señala dos sentidos fundamentales de phýsis - como materia y como forma-, ciertamente establece la prioridad de la forma como causa del ente natural y, lo que es más importante, subraya que ella no es separable más que conceptualmente (193b3-5), con clara alusión a Platón. Según esto, la forma se realiza siempre en un cuerpo; solo una forma inmanente podría ser causa del ser y del devenir de los entes naturales y explicar así tanto las propiedades esenciales como los procesos que experimenta el ente natural por sí mismo y no por la intervención de un agente exterior. Su inmanencia es una clara alternativa a la separación de las Ideas, pero es importante subrayar también que Aristóteles se apropia del carácter eterno de la Idea en su concepción de la forma. En efecto, el hecho de ser un principio interno no la vuelve corruptible como el ente natural porque su eternidad se da a través de su reproducción en otros individuos de la misma especie, en la transmisión de la forma a un individuo nuevo. ${ }^{30}$ Con esta tesis, Aristóteles asegura el contacto entre el generante y el generado y da cuenta del carácter eterno de la forma, sin necesidad de separarla de la materia y del movimiento. Así, la phýsis, en Aristóteles, permite explicar tanto las propiedades esenciales cuanto los procesos que experimentan los entes naturales, sin incurrir en los problemas que comporta la doctrina platónica. ${ }^{31}$

\footnotetext{
${ }^{30}$ Véanse, además del pasaje de De Anima 415a22-b8 analizado, Acerca de la generación y corrupción 338a2-17 y Reproducción de los animales 731b24-732a1.

${ }^{31}$ Este trabajo fue financiado por la Universidad de Buenos Aires. Programación científica 2016-2019. UBACYT, 20020150100040BA: “Diálogo, apropiación y crítica entre Platón y Aristóteles. La historia de la filosofía en la constitución de la filosofía aristotélica”.
} 


\section{BIBLIOGRAFÍA}

Angioni, L. (2008), As Noções Aristotélicas de Substância e Essência (Campinas: Unicamp). Angioni, L. (2010), "Sobre a definição de natureza”, Kriterion, 122: 521-542.

Annas, J. (1982), "Aristotle on Inefficient Causes", The Philosophical Quarterly, 32, 129: 311-326.

Berti, E. e Rossitto, C. (1993), Aristotele, Il libro primo della Metafisica (Milano: Laterza, 2002).

Besnier, B. (1997), "La définition aristotélicienne du changement (Physique, III, Ch. 1-3)”, en P.-M. Morel (ed.), Aristote et la notion de nature: Enjeux épistémologiques et pratiques (Bordeaux: Presses Universitaires, 15-34).

Boeri, M. (1993), Aristóteles, Física, Libros I-II, introducción, traducción y notas (Buenos Aires: Biblos).

Boeri, M. (2010), Aristóteles, Acerca del Alma, introducción, traducción y notas (Buenos Aires: Colihue).

Boeri, M. (2012), "Forma, función y realidad. Observaciones sobre la noción platónica y aristotélica de forma”, Estudios Públicos, 128: 187-210.

Calvo Martínez, T. (1994), Aristóteles, Metafisica, introducción, traducción y notas (Madrid: Gredos).

Centrone, B. (2002), "La critica aristotelica alla dottrina delle idee: l'argomento di Metafisica Iota 10”, en M. Migliori (ed.), Gigantomachia (Brescia: Morcelliana, 191-203).

Cherniss, H. (1944), Aristotle's Criticism of Plato and the Academy (Baltimore: Johns Hopkins Press).

Di Camillo, S. (2012), Aristóteles historiador: El examen crítico de la teoría platónica de las Ideas (Buenos Aires: UBA, Facultad de Filosofia y Letras).

Fine, G. (1987), "Forms as Causes: Plato and Aristotle", en A. Graeser (ed.), Mathematics and Metaphysics (Berne: Haupt, 69-112).

Fine, G. (1995), On Ideas:Aristotle's Criticism of Plato's Theory of Forms (Oxford: Clarendon Press).

Fischer, F. (2002), “La «méthode» et les «hypothèses» en Phédon 99d-102a”, Revue Philosophique de Louvain, 100(4): 650-80.

Fritsche, J. (2010), "Aristotle's usage of arkhé kinéseos (principle of motion) and the two definitions of nature en Physics II 1", Archiv für Begriffsgeschichte, 52: 7-31.

Fritsche, J. (2018), "Meaning and function of Aristotle's two definitions of nature (Physics B, 192b8-193a9), Physics B, and his biology", Revue de Philosophie Ancienne, 36(2): 215-287.

Fronterotta, F. (1999), "Il problema della méthexis: A proposito di un lungo dibattito platonico", Elenchos, 20(2): 397-415.

Fronterotta, F. (2010), "La critica aristotelica alla funzione causale delle Idee platoniche: Metafisica A 9. 991A8-B9”, en F. Fronterotta (ed.), La scienza e le cause a partire dalla Metafisica di Aristotele (Napoli: Bibliopolis, 93-119). 
García Gual, C. (1988), Platón, Fedón, en Diálogos III (Madrid: Gredos, 7-142).

Giardina, G. (2006), I fondamenti della causalità naturale, Analisi critica di Aristotele, Phys. II (Catania: CUECM).

Giardina, G. (2011), "Sull'uso differenziato di aitia e aition in Aristotele", en L. Couloubaritsis y S. Delcomminette (eds.), La causalité chez Aristote (Paris:Vrin, 47-82).

Gill, M. L. (2012), Philosophos: Plato's Missing Dialogue (Oxford: University Press).

Hankinson, R. (1998). Cause and Explanation in Ancient Greek Thought (Oxford: Clarendon Press).

Hayduck, M. (ed.). (1891) Alexandri Aphrodisiensis in Aristotelis Metaphysica Commentaria en Commentaria in Aristotelem Graeca, vol. I (Berlín: Reimer).

Heinemann, G. (s.f.), "Phusis, Physics, and Physicists in Aristotle" (draft). URL = $<$ https://www.academia.edu/32446489/Phusis_Physics_and_Physicists_in_ Aristotle $>$.

Kelsey, S. (2003), “Aristotle's definition of nature", Oxford Studies in Ancient Philosophy, 25: 59-87.

La Croce, E. (1987), Aristóteles. Acerca de la generación y la corrupción (Madrid: Gredos).

Lennox, J. (1985), “Are Aristotelian Species Eternal?”, en A. Gotthelf (ed.), Aristotle on Nature and Living Things (Pittsburgh: Mathesis Publications, 67-94).

Lennox, J. (2008), “As if we were Investigating Snubness: Aristotle on the Prospect of a Single Science of Nature”, Oxford Studies in Ancient Philosophy, 29: 149-86.

Quarantotto, D. (2005), Causa finale, sostanza, essenza in Aristotele: Saggio sulla struttura dei processi teleologici naturali e sulla funzione del telos (Napoli: Bibliopolis).

Reale, G. (1993), Aristotele, Metafisica, introducción, texto griego, traducción y notas, 3 vols. (Milano:Vita e Pensiero).

Robin, L. (1908), La théorie platonicienne des idées et des nombres d'après Aristote (Paris: Georg Olms Hildesheim, 1963).

Ross, W. D. (1948), Aristotle, Metaphysics, texto revisado, introducción, traducción y notas, 2 vols. (Oxford: Clarendon Press).

Rossi, G. (2011), El azar según Aristóteles (Sankt Augustin: Academia Verlag).

Sánchez, E. (1994), Aristóteles, Reproducción de los animales, introducción, traducción y notas (Madrid: Gredos).

Santa Cruz, M., Crespo, M. y Di Camillo, S. (2000), Las críticas de Aristóteles a Platón en el Tratado Sobre las Ideas (Buenos Aires: Eudeba).

Sedley, D. (1998), "Platonic Causes", Phronesis, 43, 2:114-132.

Sharma, R. (2009) "Socrates' New Aitia: Causal and Metaphysical Explanations in Plato's Phaedo", Oxford Studies in Ancient Philosophy, 36: 137-177.

Vigo, A. (2007), Aristóteles. Una introducción (Santiago: Instituto de Estudios de la Sociedad).

Vigo, A. (2009), Platón, Fedón (Buenos Aires: Colihue).

Recibido: 13-05-2020; aceptado: 28-08-2020 